\title{
Controle genético da qualidade da vagem em cruzamento de feijão-vagem e feijão-comum
}

\author{
Keny Henrique Mariguele(1), Wilson Roberto Maluf(2), Luiz Antônio Augusto Gomes(2), \\ Marcus José Conceição Lopes ${ }^{(2)}$ e Osvânder David de Melo(2)
}

\begin{abstract}
(1)Universidade Federal de Viçosa, Avenida P.H. Rolfs, s/no, Campus Universitário, CEP 36570-000 Viçosa, MG. E-mail: kmariguele@hotmail.com (2)Universidade Federal Lavras, Caixa Postal 3037, CEP 37200-000 Lavras, MG. E-mail: wrmaluf@ufla.br, luiz.gomes@pesquisador.cnpq.br, marcusjclbr@yahoo.com.br, osmelo2000@yahoo.com.br
\end{abstract}

\begin{abstract}
Resumo - O objetivo deste trabalho foi determinar os tipos principais de ações gênicas responsáveis pela expressão fenotípica de alguns caracteres de qualidade da vagem, em cruzamento de feijão-vagem e feijãocomum. Foram avaliadas duas populações segregantes $\left(\mathrm{F}_{2}\right.$ e $\left.\mathrm{F}_{2: 3}\right)$, além das linhagens parentais. Como genitora feminina, utilizou-se a cultivar de feijão-vagem Conquista Rasteiro e, como genitora masculina, a linhagem de feijão-comum H126. Foram avaliados: comprimento da vagem, largura entre as suturas, largura das valvas, formato da vagem e teor de fibra da vagem. Os efeitos não-aditivos destacaram-se em todas as características avaliadas. Embora tenha ocorrido predominância dos efeitos genéticos sobre os ambientais, nas características comprimento e formato da vagem e teor de fibra, a eficiência da seleção em plantas individuais tendeu a ser bastante baixa nas gerações segregantes pouco avançadas, em razão dos baixos valores da herdabilidade no sentido restrito, exceto para formato da vagem. O predomínio dos efeitos genéticos sobre os ambientais em todas as características em nível de família, associado a valores de herdabilidade no sentido restrito em famílias $\mathrm{F}_{2: 3}$, indica a alta eficiência para a seleção de famílias nas gerações segregantes pouco avançadas, com relação a todas as características, exceto para comprimento e teor de fibra.
\end{abstract}

Termos para indexação: Phaseolus vulgaris, ação gênica, herdabilidade, populações segregantes.

\section{Genetic control of pod quality in a cross between snap beans and common bean}

\begin{abstract}
The objective of this work was to study the main gene actions involved in phenotypic expression of pod quality in a cross between snap beans and common bean. Two segregating populations $\left(\mathrm{F}_{2}\right.$ and $\left.\mathrm{F}_{2: 3}\right)$ and the parental lines were evaluated. The snap bean cultivar Conquista Rasteiro was used as the female parent, and the common bean line H126 as the male parent. Pod length, between-suture width, valve width, pod shape, and percentage of pod fiber were evaluated. Non-additive gene effects were important for all traits evaluated. Even though genetic effects were higher than the environmental ones for pod length, pod shape, and percentage of pod fiber, efficiency of selection in individual plants tended to be low in early segregating generations, as demonstrated by the low narrow-sense heritabilities for most traits, except for pod shape. At family level, genetic effects were higher than the environmental ones for all evaluated traits, and most traits presented high narrowsense heritabilities, indicating high selection efficiency at family level in early segregating generations for all traits, except for pod length and percentage of fiber.
\end{abstract}

Index terms: Phaseolus vulgaris, gene action, heritability, segregating populations.

\section{Introdução}

O feijão-vagem pertence à mesma espécie do feijãocomum (Phaseolus vulgaris L.), e é uma das dez hortaliças mais cultivadas no Brasil, produzida, principalmente, por agricultores familiares (Peixoto et al., 2001).

Grande parte das características que distinguem o feijão-vagem do feijão-comum está relacionada à ocorrência de mutações em locos que controlam características de qualidade das vagens, que foram selecionadas e recombinadas em hibridações na Europa e nos Estados Unidos há mais de 150 anos e, possivelmente, também na China (Silbernagel, 1996).

No Brasil, tradicionalmente, pouca atenção tem sido dedicada ao melhoramento do feijão-vagem. Em geral, os agricultores têm sido os principais responsáveis pela seleção e manutenção de cultivares. As populações locais são freqüentemente mantidas pelos agricultores ou 
produzidas comercialmente por companhias de sementes. Além disso, grande esforço tem sido dedicado ao melhoramento genético do feijoeiro destinado ao consumo como grãos, de modo que estão disponíveis no Brasil inúmeras e excelentes cultivares de feijão-comum, resistentes a doenças, notadamente à antracnose (Albuquerque et al., 2002; Abreu et al., 2003; Faleiro et al., 2003; Pereira et al., 2004; Theodoro, 2004; Couto et al., 2005; Carvalho et al., 2006; Antunes et al., 2007; Carvalho \& Wanderley, 2007).

Embora desejável, o uso de cultivares melhoradas de feijão-comum no melhoramento de feijão-vagem, com o fim de aumentar a resistência a doenças, tem sido limitado, em grande parte, pelas dificuldades de se recuperar tipos hortícolas com qualidade de vagem (comprimento, formato, teor de fibra) aceitáveis para o mercado consumidor.

$\mathrm{O}$ conhecimento da natureza e da magnitude dos efeitos gênicos que controlam um caráter é primordial para o processo de seleção e para a predição do comportamento das gerações segregantes (Cruz et al., 2004). As informações sobre o controle genético de caracteres, ligados à qualidade da vagem em feijão, são escassas na literatura. Sua importância está na tomada de decisões quanto aos métodos a serem seguidos ou ao tamanho de população a ser conduzida, durante a execução do programa de melhoramento.

O objetivo deste trabalho foi determinar os tipos principais de ações gênicas, responsáveis pela expressão fenotípica de alguns caracteres de importância relacionados à vagem, em cruzamento de uma cultivar de feijão-vagem e uma de feijão-comum.

\section{Material e Métodos}

Os experimentos foram realizados na Estação Experimental da HortiAgro Sementes Ltda., na fazenda Palmital, em Ijaci, MG $\left(21^{\circ} 14^{\prime} \mathrm{S}, 45^{\circ} 8^{\prime} \mathrm{W}, 920 \mathrm{~m}\right.$ de altitude, temperatura média entre $18 \mathrm{e} 21^{\circ} \mathrm{C}$ e precipitação pluvial entre 1.100 e $2.000 \mathrm{~mm}$, com estação chuvosa de aproximadamente cinco meses).

Na obtenção das gerações segregantes, foi utilizada, como genitora feminina, a cultivar de feijão-vagem Conquista Rasteiro e, como masculina, a linhagem de feijão-comum H126. A 'Conquista Rasteiro' é oriunda da empresa Hortec Sementes e possui vagens do tipo macarrão, com sementes brancas e hábito de crescimento determinado. A 'H126' é oriunda do programa de melhoramento do feijão-comum, da
Universidade Federal de Lavras, e possui o alelo Co- $4^{2}$ de resistência à antracnose, grãos do tipo carioca e vagens pequenas, achatadas, com formato típico das cultivares de feijão comumente utilizadas, e elevado teor de fibras nas vagens.

Os experimentos foram conduzidos com as gerações $\mathrm{F}_{2}$ e $\mathrm{F}_{2: 3}$, além das linhagens parentais. $\mathrm{O}$ primeiro experimento foi semeado no dia 14/3/2005, com os genitores e a geração $\mathrm{F}_{2}$, em delineamento inteiramente ao acaso, composto de 140 parcelas, com quatro plantas por parcela, espaçadas de $25 \mathrm{~cm}$ dentro da parcela e $30 \mathrm{~cm}$ entre as parcelas. Das 140 parcelas, 20 corresponderam a cada um dos pais e 100 à geração $\mathrm{F}_{2}$. Foram colhidas sementes na população $\mathrm{F}_{2}$, em plantas individuais, tendo-se obtido famílias $\mathrm{F}_{2: 3}$.

$\mathrm{O}$ segundo experimento foi semeado com escalonamento do plantio das repetições (blocos) em 15 dias. A primeira repetição foi semeada no dia $6 / 2 / 2006$, com sementes $F_{2: 3}$ colhidas em cada planta $F_{2}$, além das linhagens parentais. Neste experimento, 110 tratamentos foram plantados em cinco repetições (blocos), com o mesmo número de plantas e espaçamento do experimento anterior. Desses 110 tratamentos, 100 corresponderam a famílias $F_{2: 3}$ (não selecionadas previamente para nenhuma característica agronômica), e cinco corresponderam a cada uma das linhagens parentais. Utilizou-se irrigação por gotejamento e tratos culturais recomendados para a cultura.

As colheitas, para efeito das avaliações da qualidade da vagem, foram efetuadas quando a cultivar parental 'Conquista Rasteiro' atingiu o estágio de vagens comerciais.

Os dados das características avaliadas foram obtidos com base em três vagens, colhidas de cada planta.

As características avaliadas foram: comprimento da vagem - medida longitudinal entre a base e o ápice da vagem $(\mathrm{mm})$; largura $1\left(\mathrm{~L}_{1}\right)$ - medida do diâmetro transversal de uma sutura a outra, na posição central das vagens $(\mathrm{mm})$; largura $2\left(\mathrm{~L}_{2}\right)$ - medida da largura das valvas, na posição central das vagens $(\mathrm{mm})$; formato da vagem - relação de medida $\mathrm{L}_{2} / \mathrm{L}_{1}$ que indica o formato da vagem, ou seja, valor próximo de 1 indica formato cilíndrico, tendente ao tipo macarrão e, valor próximo de 0 indica vagem achatada, tendente ao tipo manteiga; nota para formato de vagem - atribuiu-se nota de 1 a 5, em que 1 representa vagens cilíndricas e 5, vagens achatadas; tanto a relação $\mathrm{L}_{2} / \mathrm{L}_{1}$ quanto a nota são formas de medir o mesmo caráter, e a avaliação por meio de notas, além de ter sido mais rápida, considerou todo o comprimento 
da vagem; teor de fibra - três vagens in natura foram trituradas por 1 min no liquidificador, em seguida as amostras foram peneiradas (30 mesh), lavadas em água corrente e, posteriormente, secadas em estufa de circulação forçada de ar, até peso constante. O resultado foi expresso em percentagem de fibras relativamente ao peso fresco das vagens (Rodrigues et al., 1998).

Utilizando-se os dados médios, foram estimados os componentes de média, pelo método dos quadrados mínimos ponderados (Rowe \& Alexander, 1980; Mather \& Jinks, 1984; Ramalho et al., 1993). Considerou-se o modelo aditivo e dominante sem epistasia, conforme a expressão:

$$
\hat{B}=\left(X^{\prime} X\right)^{-1} X^{\prime} Y
$$

$$
\hat{B}=\left|\begin{array}{c}
\hat{m} \\
\hat{a} \\
\hat{d}
\end{array}\right| \quad X=\left|\begin{array}{ccc}
1 & -1 & 0 \\
1 & 1 & 0 \\
1 & 0 & 1 / 2 \\
1 & 0 & 1 / 4
\end{array}\right| \quad Y=\left|\begin{array}{l}
\hat{m}_{P_{1}} \\
\hat{m}_{P_{2}} \\
\hat{m}_{F_{2}} \\
\hat{m}_{F_{2: 3}}
\end{array}\right|
$$

em que [m] é a média fenotípica dos genótipos homozigóticos; [a] é o desvio dos homozigotos, em relação ao ponto médio; [d] é o desvio do heterozigoto, em relação ao ponto médio; $\hat{m}_{p_{1}}$ é a estimativa da média do pai $1 ; \hat{m}_{p_{2}}$ é a estimativa da média do pai $2 ; \hat{m}_{F_{2}}$ é a estimativa da média da geração $\mathrm{F}_{2}$; e $\hat{m}_{F_{2: 3}}$ é a estimativa da média da geração $F_{2: 3}$.

Estimaram-se também os componentes de variância, pelo método dos quadrados mínimos ponderados (Mather \& Jinks, 1984; Ramalho et al., 1993):

$$
\begin{aligned}
& \hat{B}=\left(X^{\prime} X\right)^{-1} X^{\prime} Y \\
& \hat{B}=\left|\begin{array}{c}
\hat{\sigma}_{A}^{2} \\
\hat{\sigma}_{D}^{2} \\
\hat{\sigma}^{2} \\
\hat{e}_{(W)}^{2} \\
\hat{\sigma}_{e_{(B)}}^{2}
\end{array}\right| \quad X=\left|\begin{array}{cccc}
1 & 1 & 1 & 0 \\
1 & 1 / 4 & 0 & 1 \\
1 / 2 & 1 / 2 & 1 & 0 \\
1 & 1 / 2 & 0 & 0 \\
0 & 0 & 1 & 0
\end{array}\right| \quad Y=\left|\begin{array}{c}
\hat{\sigma}_{F_{2}}^{2} \\
\hat{\sigma}_{F_{2: 3}}^{2} \\
\hat{\sigma}_{d F_{2: 3}}^{2} \\
\operatorname{Cov}_{F_{2}, \bar{F}_{2: 3}} \\
\hat{\sigma}_{e}^{2}
\end{array}\right|,
\end{aligned}
$$

em que $\hat{\sigma}_{A}^{2}$ é a estimativa da variância genética aditiva; $\hat{\sigma}_{D}^{2}$ é a estimativa da variância genética de dominância;
$\hat{\sigma}_{e_{(W)}}^{2}$ é a estimativa da variância ambiental entre plantas; $\hat{\sigma}_{e_{(B)}}^{2}$ é a estimativa da variância ambiental entre famílias; $\hat{\sigma}_{F_{2}}^{2}$ é a estimativa da variância fenotípica entre plantas da geração $\mathrm{F}_{2} ; \hat{\sigma}_{F_{2: 3}}^{2}$ é a estimativa da variância fenotípica entre famílias $\mathrm{F}_{2: 3} ; \hat{\sigma}_{d F_{2: 3}}^{2}$ é a estimativa da variância fenotípica entre plantas dentro de famílias $\mathrm{F}_{2: 3}$; $\operatorname{Cov}_{F_{2}}, \bar{F}_{2: 3}$ é a estimativa da covariância entre plantas da geração $\mathrm{F}_{2}$ e a média de famílias da geração $\mathrm{F}_{2: 3} ; \hat{\sigma}_{e}^{2}$ é a estimativa da variância ambiental entre plantas, calculada a partir das plantas dos genitores masculinos e femininos.

Para se obterem as estimativas dos componentes de variância $\left(\hat{\sigma}_{A}^{2}, \hat{\sigma}_{D}^{2}, \hat{\sigma}_{e}^{2}\right)$, utilizaram-se restrições de estimativas maiores/iguais a zero, pela ferramenta Solver do Microsoft Excel, apropriado para programação linear.

As herdabilidades para todas as características foram estimadas de acordo com as seguintes expressões:

$$
\hat{h}_{a}^{2}=\frac{\hat{\sigma}_{A}^{2}+\hat{\sigma}_{D}^{2}}{\hat{\sigma}_{A}^{2}+\hat{\sigma}_{D}^{2}+\hat{\sigma}_{e_{(W)}}^{2}} \text { e } \hat{h}_{a_{\left(F_{3}\right)}}^{2}=\frac{\hat{\sigma}_{A}^{2}+1 / \hat{\sigma}_{D}^{2}}{\hat{\sigma}_{A}^{2}+1 / 4 \hat{\sigma}_{D}^{2}+\hat{\sigma}_{e_{(B)}}^{2}} \text {, }
$$

para as estimativas das herdabilidades no sentido amplo, em plantas e em famílias $\mathrm{F}_{2: 3}$, respectivamente;

$$
\hat{h}_{r}^{2}=\frac{\hat{\sigma}_{A}^{2}}{\hat{\sigma}_{A}^{2}+\hat{\sigma}_{D}^{2}+\hat{\sigma}_{e_{(W)}}^{2}} \text { e } \hat{h}_{r_{\left(F_{3}\right)}}^{2}=\frac{\hat{\sigma}_{A}^{2}}{\hat{\sigma}_{A}^{2}+1 / \hat{\sigma}_{D}^{2}+\hat{\sigma}_{e_{(B)}}^{2}},
$$

para as estimativas das herdabilidades no sentido restrito, em plantas e em famílias $\mathrm{F}_{2: 3}$, respectivamente.

Os coeficientes de correlação genética entre pares de características avaliadas foram estimados com os dados fenotípicos da geração $F_{2}$ de uma das características, e a média das famílias $\mathrm{F}_{2: 3}$ da outra característica.

\section{Resultados e Discussão}

O caráter comprimento da vagem apresentou o componente de média [d], inferior a [a] (Tabela 1), o que mostra que, aparentemente, os efeitos aditivos foram mais importantes do que os não-aditivos. No entanto, quando se analisaram os componentes de variância, observou-se valor elevado para o componente nãoaditivo de $\hat{\sigma}_{D}^{2}$, comparado ao valor nulo para $\hat{\sigma}_{A}^{2}$ (Tabela 2). Isso se explica pelo fato de o valor [d] ser 
obtido pelo somatório dos desvios, de modo que valores com sinais contrários podem se anular. $\mathrm{O}$ valor elevado de $\hat{\sigma}_{D}^{2}$, associado ao baixo valor [d], permite concluir que esse caráter é controlado, principalmente, por alelos dominantes. Porém, tais alelos não atuam todos no mesmo sentido, isto é, há alelos dominantes que tendem a aumentar o comprimento da vagem, mas há também alelos dominantes que atuam para diminuir o comprimento. As estimativas dos componentes de variância possibilitaram a obtenção da verdadeira estimativa dos efeitos genéticos, uma vez que, mesmo tendo ocorrido desvios de sinais opostos, esses não se cancelaram, pois os efeitos individuais de cada loco foram elevados ao quadrado. Rodrigues et al. (1998), utilizaram dialelo de feijão-vagem x feijão-comum, e Dickson (1967), Singh (1991) e Carvalho et al. (1999) utilizaram dialelo de feijão-vagem $x$ feijão-vagem $\mathrm{e}$ encontraram efeitos aditivos para esse caráter, mas as conclusões desses autores não se basearam na análise de cruzamentos biparentais, como neste trabalho.

Para a $\mathrm{L}_{1}$, o grau médio de dominância $[\mathrm{d}] /[\mathrm{a}]$ indica que os efeitos não-aditivos foram maiores (Tabela 1), confirmado pelo valor de $\hat{\sigma}_{D}^{2}(0,5675)$ superior à $\hat{\sigma}_{A}^{2}$ $(0,3103)$ (Tabela 2). Para essa característica, valores elevados de $\mathrm{L}_{1}$ são dominantes em relação a baixos valores. Esse sentido de dominância é indicado pelo sinal positivo de [d] (Tabela 1).

Para os caracteres $\mathrm{L}_{2}$ e $\mathrm{L}_{2} / \mathrm{L}_{1}$, os graus médios de dominância foram próximos de 1 para $\mathrm{L}_{2}$ e superiores a 1 para $\mathrm{L}_{2} / \mathrm{L}_{1}$, o que mostra que os efeitos não-aditivos também se destacaram; no entanto, as estimativas de $\hat{\sigma}_{D}^{2}$ foram nulas para ambas características (Tabela 2). Uma possível explicação para valores elevados absolutos de [d], associados às baixas estimativas de $\hat{\sigma}_{D}^{2}$, seria o

Tabela 1. Estimativas dos componentes de médias e grau de dominância, quanto a: comprimento da vagem (Comp), largura transversal $\left(\mathrm{L}_{1}\right)$, largura entre as valvas $\left(\mathrm{L}_{2}\right)$, relação $\mathrm{L}_{2} / \mathrm{L}_{1}$, nota para formato de vagem e percentagem de fibra.

\begin{tabular}{lrrrr}
\hline Caráter & \multicolumn{3}{c}{ Componentes de média } & \multicolumn{2}{c}{ Grau de dominância } \\
\cline { 2 - 4 } & \multicolumn{1}{c}{$[\mathrm{m}]$} & \multicolumn{1}{c}{$[\mathrm{a}]$} & \multicolumn{1}{c}{$[\mathrm{d}]$} & {$[\mathrm{d}] /[\mathrm{a}]$} \\
\hline Comp & 117,59 & 13,54 & $-1,95$ & $-0,14$ \\
$\mathrm{~L}_{1}$ & 8,90 & 0,92 & 1,20 & 1,30 \\
$\mathrm{~L}_{2}$ & 6,67 & 0,94 & $-0,77$ & $-0,81$ \\
$\mathrm{~L}_{2} / \mathrm{L}_{1}$ & 0,77 & 0,19 & $-0,22$ & $-1,14$ \\
Nota & 2,93 & 1,73 & 2,30 & 1,33 \\
Fibra $(\%)$ & 4,78 & 3,48 & 2,47 & 0,71 \\
\hline
\end{tabular}

(1)[m]: média fenotípica dos genótipos homozigóticos; [a]: desvio dos homozigotos, em relação ao ponto médio; [d]: desvio do heterozigoto, em relação ao ponto médio. controle genético dessas características por numerosos alelos com ação gênica dominante e unidirecional: [d] seria o somatório de efeitos lineares de um grande número de alelos dominantes, todos atuantes numa mesma direção, enquanto o $\hat{\sigma}_{D}^{2}$ seria pequeno, por representar o somatório de um grande número de variâncias de baixo valor. Os sinais negativos de [d] para $\mathrm{L}_{2}(-0,77)$ e $\mathrm{L}_{2} / \mathrm{L}_{1}(-0,22)$ indicaram que baixos valores de $L_{2}$ são dominantes em relação a valores elevados, e o formato achatado é dominante em relação ao formato cilíndrico (Tabela 1).

Para nota da vagem, o valor de $[\mathrm{d}] /[\mathrm{a}]$ sugere predomínio dos efeitos não-aditivos (Tabela 1), assim como relatado por Rodrigues et al. (1998) quanto ao formato da vagem. Porém, a estimativa de $\hat{\sigma}_{A}^{2}$ foi superior à $\hat{\sigma}_{D}^{2}$ (Tabela 2). Isso se explica, como já comentado anteriormente, quando se considera a herança poligênica com dominância unidirecional. O sinal positivo de [d] $(2,30)$ indica, assim como para $\mathrm{L}_{2} / \mathrm{L}_{1}$, que menores valores de $\mathrm{L}_{2}$ são dominantes em relação a maiores valores, e formato achatado é dominante em relação a formato cilíndrico, conclusão semelhante à encontrada para a característica $\mathrm{L}_{2} / \mathrm{L}_{1}$.

Quanto ao teor de fibra, o valor de $[\mathrm{d}] /[\mathrm{a}](0,71)$ indica que os efeitos não-aditivos também foram mais importantes para esse caráter. $\mathrm{O}$ sinal positivo de [d] $(2,47)$ indica que o alto teor de fibra é dominante em relação ao baixo teor de fibra (Tabela 1). Rodrigues et al. (1998) e Carvalho et al. (1999) encontraram resultados semelhantes para esse caráter. A estimativa de $\hat{\sigma}_{D}^{2}$ foi maior que $\sigma_{A}^{2}$ Tabela 2). Uma vez que no melhoramento do feijão-vagem, o objetivo é se obterem linhas

Tabela 2. Estimativas dos componentes de variâncias quanto a: comprimento da vagem (Comp), largura transversal $\left(\mathrm{L}_{1}\right)$, largura entre as valvas $\left(\mathrm{L}_{2}\right)$, relação $\mathrm{L}_{2} / \mathrm{L}_{1}$, nota para formato de vagem e percentagem de fibra.

\begin{tabular}{lrrrr}
\hline Caráter & \multicolumn{4}{c}{ Variâncias $^{(1)}$} \\
\cline { 2 - 5 } & $\hat{\sigma}^{2}{ }_{A}$ & \multicolumn{1}{c}{$\hat{\sigma}^{2}$} & $\hat{\sigma}^{2}$ & $\hat{\sigma}_{(W)}{ }^{2}$ \\
& 0,0000 & 555,4267 & 101,6043 & 0,0000 \\
Comp & 0,3103 & 0,5675 & 1,4361 & 0,1150 \\
$\mathrm{~L}_{1}$ & 0,3134 & 0,0000 & 0,8007 & 0,2637 \\
$\mathrm{~L}_{2}$ & 0,0136 & 0,0000 & 0,0083 & 0,0012 \\
$\mathrm{~L}_{2} / \mathrm{L}_{1}$ & 0,8077 & 0,3436 & 0,3167 & 0,0224 \\
Nota & 0,0000 & 2,9193 & 3,6674 & 0,7788 \\
Fibra (\%) &
\end{tabular}

${ }^{(1)} \hat{\sigma}^{2}$ : variância genética aditiva; $\hat{\sigma}_{D}^{2}$ : variância genética de dominância; $\hat{\sigma}_{e(W)}^{{ }^{A}}$ : variância ambiental entre plantas; $\sigma_{e(B)}^{2}$ : variância ambiental entre famílias. 
homozigotas, e os efeitos não-aditivos não podem ser fixados, a maior magnitude de $\hat{\sigma}_{D}^{2}$ indica dificuldade em se prever o comportamento de uma geração, a partir do comportamento da geração precedente.

$\wedge$ Quanto às herdabilidades em plantas $F_{2}$ no sentido amplo, $h_{\mathrm{a}}^{2}$, observa-se que as estimativas variaram de baixa $\left(\mathrm{L}_{2}\right) \mathrm{e}$ moderadamente elevadas $\left(\mathrm{L}_{1}\right.$ e teor de fibra) a elevadas, para as demais características (Tabela 3). Estimativas elevadas ou moderadamente elevadas para algumas características indicam a predominância dos efeitos genéticos sobre os ambientais, nesses casos. As estimativas de $\hat{h}_{\mathrm{r}}^{2}$ foram baixas para todas as características, exceto para formato $\left(\mathrm{L}_{2} / \mathrm{L}_{1}\right.$ e nota), o que indica que, embora tenha ocorrido predomínio dos efeitos genéticos sobre os ambientais em algumas características, a eficiência da seleção em plantas individuais tende a ser bastante baixa nas gerações segregantes pouco avançadas, em razão dos baixos valores de $\hat{h}_{\mathrm{r}}^{2}$ (que é função da variância genética aditiva, ou seja, da porção da variância genética que pode ser fixada com a seleção), com exceção dos caracteres relacionados ao formato da vagem $\left(\mathrm{L}_{2} / \mathrm{L}_{1}\right.$ e nota).

As estimativas das herdabilidades encontradas nos trabalhos citados por Singh (1991), para o comprimento da vagem, variaram de 0,53 a 0,91 no sentido amplo (altas conforme as encontradas neste trabalho), e de 0,53 a 0,70 no sentido restrito (superiores às encontradas neste trabalho). Para os demais caracteres, não foram encontradas referências na literatura.

As estimativas das herdabilidade em famílias $\mathrm{F}_{2: 3}$ no sentido amplo $\left(\hat{h}_{\mathrm{a}_{\left(\mathrm{F}_{2 \cdot 3}\right)}^{2}}\right)$ variaram de moderadamente elevadas $(0,48$ para teor de fibra) a elevadas (demais características), e houve o predomínio dos efeitos genéticos sobre os ambientais, em todas as características avaliadas (Tabela 3). Conforme esperado, essas estimativas foram superiores àquelas observadas na geração $\mathrm{F}_{2}$, que foram calculadas em plantas individuais. As estimativas no sentido restrito foram elevadas para todas as características, exceto para comprimento e teor de fibra, em razão da estimativa nula obtida para $\hat{\sigma}_{A}^{2}$. Valores elevados de $\hat{h}_{\left.\mathrm{r}_{(}\right)}^{2}$ indicam a elevada eficiência de seleção de famílias nàs gerações segregantes pouco avançadas, para todas as características, exceto para comprimento de vagem e teor de fibra.

Os coeficientes de correlação foram baixos entre todos os caracteres avaliados, exceto $\mathrm{L}_{2} / \mathrm{L}_{1}$ e nota para formato da vagem (Tabela 4), por refletirem diferentes modos de analisar o formato da vagem. Baixos coeficientes de correlação genética refletem a eficiência em se selecionar um caráter sem benefício e/ou prejuízo do outro.
Tabela 3. Estimativas de herdabilidade, no sentido amplo e restrito, em plantas $\mathrm{F}_{2}\left(h_{\mathrm{a}}^{2}\right.$ e $\left.h_{\mathrm{r}}^{2}\right)$ e em famílias $\mathrm{F}_{3} \hat{(h}_{\mathrm{a}_{\left(\mathrm{F}_{2: 3}\right)}^{2}} \mathrm{e}$ $\left.\hat{h}_{\mathrm{r}_{\left(\mathrm{F}_{3}\right)}}^{2}\right)$, quanto a: comprimento da vagem (Comp), largura transversal $\left(\mathrm{L}_{1}\right)$, largura entre as valvas $\left(\mathrm{L}_{2}\right)$, relação $\mathrm{L}_{2} / \mathrm{L}_{1}$, nota para formato de vagem e percentagem de fibra.

\begin{tabular}{lccccc}
\hline Caráter & \multicolumn{2}{c}{ Plantas $\mathrm{F}_{2}$} & & \multicolumn{2}{c}{ Famílias $\mathrm{F}_{2: 3}$} \\
\cline { 2 - 3 } \cline { 5 - 6 } & $\hat{h}_{a}^{2}$ & $\hat{h}_{r}^{2}$ & & $\hat{h}_{a_{\left(F_{2: 3}\right)}}^{2}$ & $\hat{h}_{r_{\left(F_{3}\right)}}$ \\
\hline Comp & 0,84 & 0,00 & & 1,00 & 0,00 \\
$\mathrm{~L}_{1}$ & 0,38 & 0,13 & & 0,80 & 0,55 \\
$\mathrm{~L}_{2}$ & 0,28 & 0,28 & & 0,54 & 0,54 \\
$\mathrm{~L}_{2} / \mathrm{L}_{1}$ & 0,62 & 0,62 & & 0,92 & 0,92 \\
Nota & 0,78 & 0,55 & & 0,98 & 0,88 \\
Fibra (\%) & 0,44 & 0,00 & & 0,48 & 0,00 \\
\hline
\end{tabular}

Tabela 4. Estimativas das correlações genéticas $\left(\mathrm{r}_{\mathrm{G}}\right)$ quanto a: comprimento da vagem (Comp), largura transversal $\left(\mathrm{L}_{1}\right)$, largura entre as valvas $\left(\mathrm{L}_{2}\right)$, relação $\mathrm{L}_{2} / \mathrm{L}_{1}$, nota para formato de vagem e percentagem de fibra.

\begin{tabular}{lccccc}
\hline Caráter & $\mathrm{L}_{1}$ & $\mathrm{~L}_{2}$ & $\mathrm{~L}_{2} / \mathrm{L}_{1}$ & Nota & Fibra (\%) \\
\hline Comp & 0,14 & $-0,13$ & $-0,18$ & 0,16 & $-0,21$ \\
$\mathrm{~L}_{1}$ & - & $-0,41$ & $-0,63$ & 0,62 & $-0,22$ \\
$\mathrm{~L}_{2}$ & & - & 0,64 & $-0,62$ & $-0,05$ \\
$\mathrm{~L}_{2} / \mathrm{L}_{1}$ & & & - & $-0,83$ & 0,09 \\
Nota & & & & - & $-0,06$ \\
Fibra (\%) & & & & & - \\
\hline
\end{tabular}

\section{Conclusões}

1. Os efeitos não-aditivos são mais importantes, em todas as características avaliadas.

2. A eficiência da seleção em plantas individuais tende a ser bastante baixa, nas gerações segregantes pouco avançadas.

3. A eficiência de seleção em famílias, nas gerações segregantes pouco avançadas, é alta para todas as características, exceto para comprimento e teor de fibra.

4. Os coeficientes de correlação são baixos entre todas as características avaliadas, exceto $\mathrm{L}_{2} / \mathrm{L}_{1}$ e nota.

\section{Agradecimentos}

Ao Conselho Nacional de Desenvolvimento Científico e Tecnológica $(\mathrm{CNPq})$, pela concessão de bolsa; à Fundação de Amparo à Pesquisa do Estado de Minas Gerais, ao CNPq, à Coordenação de Aperfeiçoamento de Pessoal de Nível Superior e à HortiAgro Sementes Ltda., pelo apoio financeiro. 


\section{Referências}

ABREU, A. de F.B.; RAMALHO, M.A.P.; GONÇALVES, F.M.A.; MENDONÇA, H.A. de. Utilização da produtividade de grãos na seleção para resistência ao Colletotrichum lindemuthianum no feijoeiro. Ciência e Agrotecnologia, v.27, p.363-369, 2003.

ALBUQUERQUE, M.M. de; VIEIRA, J.C.; LEMOS, J.W.V.; OLIVEIRA, F.F. de; SANTOS, J.F. dos. Avaliação de linhagens e cultivares de feijão carioca nas regiões do Agreste e Sertão de Alagoas. Comunicado Técnico, v.4, 2002. 9p. (Embrapa Tabuleiros Costeiros).

ANTUNES, I.F.; SILVEIRA, E.P.; SILVA, H.T. da. BRS Expedito: nova cultivar de feijão de grãos pretos. Pesquisa Agropecuária Brasileira, v.42, p.135-136, 2007.

CARVALHO, A.C.P.P. de; LEAL, N.R.; RODRIGUES, R.; COSTA, F.A. Capacidade de combinação para oito caracteres agronômicos em cultivares rasteiras de feijão-vagem. Horticultura Brasileira, v.17, p.102-105, 1999.

CARVALHO, W.P. de; WANDERLEY, A.L. Avaliação de cultivares de feijão (Phaseolus vulgaris) para o plantio em sistema orgânico no Distrito Federal. Ciência e Agrotecnologia, v.31, p.605-611, 2007.

CARVALHO, W.P. de; WANDERLEY, A.L.; FERNANDES, A. de M. Comportamento de cultivares de feijoeiro em áreas de conversão para o sistema orgânico de produção no Cerrado. Pesquisa Agropecuária Tropical, v.36, p.205-210, 2006.

COUTO, M.A.; SANTOS, J.B. dos; FERREIRA, J.L. Melhoramento do feijoeiro-comum com tipo de grão carioca visando resistência à antracnose e à mancha-angular. CONGRESSO NACIONAL DE PESQUISA DE FEIJÃO, 8., 2005, Goiânia. Anais. Goiânia: Embrapa Arroz e Feijão, 2005. p.505-508. (Embrapa Arroz e Feijão. Documentos, 182). Disponível em: www.cnpaf.embrapa.br/conafe/pdf/conafe2005-0042.pdf. Acesso em: 7 ago. 2006.

CRUZ, C.D.; REGAZZI, A.J.; CARNEIRO, P.C.S. Modelos biométricos aplicados ao melhoramento genético. 3.ed. Viçosa: UFV, 2004. v.1. 480p.
DICKSON, M.H. Diallel analysis of seven economic characters in snap beans. Crop Science, v.7, p.121-124, 1967.

FALEIRO, F.G.; RAGAGNIN, V.A.; SCHUSTER, I.; CORRÊA, R.X.; GOOD-GOD, P.J.; BROMMONSHENKEL, S.H.; MOREIRA, M.A.; BARROS, E.G. Mapeamento de genes de resistência do feijoeiro à ferrugem, antracnose e mancha-angular usando marcadores RAPD. Fitopatologia Brasileira, v.28, p.5966, 2003.

MATHER, K.; JINKS, L.L. Introdução à genética biométrica. Ribeirão Preto: Sociedade Brasileira de Genética, 1984. 242p.

PEIXOTO, N.; MORAIS, E.A.; MONTEIRO, J.D.; THUNG, M.D.T. Seleção de linhagens de feijão-vagem de crescimento indeterminado para cultivo no Estado de Goiás. Horticultura Brasileira, v.19, p.85-88, 2001.

PEREIRA, H.S.; SANTOS, J.B. dos; ABREU, A. de F.B. Linhagens de feijoeiro com resistência à antracnose selecionadas quanto a características agronômicas desejáveis. Pesquisa Agropecuária Brasileira, v.39, p.209-214, 2004.

RAMALHO, M.A.P.; SANTOS, J.B. dos; ZIMMERMANN, M.J. de O. Genética quantitativa em plantas autógamas: aplicações ao melhoramento do feijoeiro. Goiânia: UFG, 1993. 271p.

RODRIGUES, R.; LEAL, N.R.; PEREIRA, M.G. Análise dialélica de seis características agronômicas em Phaseolus vulgaris L. Bragantia, v.57, p.241-250, 1998.

ROWE, K.E.; ALEXANDER, W.L. Computations for estimating the genetic parameters in joint-scaling tests. Crop Science, v.20, p.109-110, 1980.

SILBERNAGEL M.J. Snap bean breeding. In: BASSETT, M.J. (Ed.). Breeding vegetable crops. Westport: The AVI, 1996. p.243282.

SINGH, S.P. Bean genetics. In.: VAN SCHOONHAVEN, A.; VOYSEST, O. (Ed.). Common beans: research for crop improvement. Melksham: Oxford University Press, 1991. p.199-255.

THEODORO, G. de F. Reação de cultivares locais de feijão a Xanthomonas axonopodis pv. phaseoli, em condições de campo. Revista Brasileira de Agrociência, v.10, p.373-375, 2004.

Recebido em 17 de julho de 2007 e aprovado em 20 de dezembro de 2007 